Fanum,

Sociológico

\section{Forum Sociológico}

Série II

22 | 2012

Saúde e multiculturalidade

\title{
Na periferia do fenómeno da peopolização: o telemóvel e a telenovela
}

José Augusto dos Santos Alves

\section{(2) OpenEdition}

Journals

Edição electrónica

URL: https://journals.openedition.org/sociologico/650

DOI: 10.4000/sociologico.650

ISSN: 2182-7427

Editora

CICS.NOVA - Centro Interdisciplinar de Ciências Sociais da Universidade Nova de Lisboa

Refêrencia eletrónica

José Augusto dos Santos Alves, «Na periferia do fenómeno da peopolização: o telemóvel e a

telenovela», Forum Sociológico [Online], 22 | 2012, posto online no dia 26 fevereiro 2013, consultado o 31 março 2022. URL: http://journals.openedition.org/sociologico/650 ; DOI: https://doi.org/10.4000/ sociologico.650

Este documento foi criado de forma automática no dia 31 março 2022.

(C) CICS.NOVA 


\section{Na periferia do fenómeno da peopolização: o telemóvel e a telenovela}

José Augusto dos Santos Alves

\section{Introdução}

1 Como definir peopolização? Peopolização é o nome dado por Dominique Wolton às práticas dos meios de comunicação que fortalecem a chamada sociedade do espetáculo, como o reality show, com o culto das celebridades, mesmo que sejam celebridades produzidas, instantâneas e efémeras (Wolton, 2006: 66; 2007).

2 No mesmo sentido vai Dakhlia, quando aborda as especulações mediáticas sobre os segredos de alcova dos nossos dirigentes ou ainda o "buzz" de vídeos mostrando, sob luz comprometedora, a exibição de um certo número deles ao lado de vedetas do desporto ou do showbiz, fazendo com que todos estes fenómenos, entre tantos outros, sejam imputados hoje a uma peopolização galopante da nossa sociedade. O que se entende, exatamente, por peopolização? A etimologia da palavra conduz, na ocorrência, ao termo "people". De toda a maneira, é necessário saber de que "people" se fala. A adequação à língua portuguesa, que aqui faço, do vocábulo da língua francesa "peopolisation" e da palavra inglesa people, à partida sinónimo de "povo" ou de "gente", realiza-se à custa da contração da sua significação.

3 A peopolização designa especificamente um indivíduo ou categoria de indivíduos conhecidos pela sua mediatização ou, se quisermos, de maneira metonímica, os media orientados sobre a vida, privada sobretudo, destas personagens "célebres". Este duplo sentido orienta-nos imediatamente para o caráter profundamente performativo do people. Na verdade, desde que o discurso people se aproprie de um indivíduo, seja de que estatuto for - artista, atleta, cabeça coroada, político, modelo fashion, ou simples anónimo -, erige-o ipso facto em people. "De même, parler de people revient-il toujours, peu ou prou, à faire du people, ce qui explique en partie pourquoi la peopolisation est 
souvent perçue comme une extension irrésistible du domaine du people" (Dakhlia, 2010: 6).

4 Aprofundando a noção, pode dizer-se que a peopolização é a extensão da mediatização do mundo do show business a outros meios (político, cultural, desportivo, etc.), à mediatização da vida privada das personalidades, à utilização das vedetas para fins de relações públicas, à fabricação e utilização económica das estrelas do desporto e do show business, inclusive a adoção pelos media generalistas de certos comportamentos da imprensa people, etc.

Numa primeira abordagem, sobre a base de um sobreinvestimento coletivo da celebridade, a peopolização surge como um mito naï, segundo o qual a celebridade representa o summum da realização pessoal e do sucesso social. A eficácia deste mito está próxima de um certo número de candidatos da tele-"realidade" ou de "microcelebridades" da tela, cuja principal aspiração "na vida" será "tornar-se" people, como se tratasse de uma profissão ou de uma vocação.

\section{As "litanias" periféricas da peopolização}

6 Neste contexto, é necessário reconhecer que a maioria do público se entrega com bemaventurança a esta crença na salvação pela peopolização, uma constatação que conduz ao tema central deste texto, o telemóvel e a telenovela, como prodígios periféricos do desejo de ser people. Este género de crença tem outros tipos de manifestações, e. g., o horóscopo, um ingrediente imprescindível, que trago à colação, porque, "apimentando" o caldo de cultura das aparências, melhora a inteligibilidade deste processo de submissão dos crentes ao mundo people, que, sob a luz dos holofotes, por entre as câmaras de televisão e os flashes dos fotógrafos, exibe uma vida que corre delirante mas sempre a sorrir. As imperfeições não existem, as mágoas também não.

7 Na verdade, este tipo de "fé" revela-se em expressões como os signos e o horóscopo, na essência, um trabalho dos videntes do embuste e da impostura, um exercício subtil que exige grande habilidade. $\mathrm{O}$ horóscopo, condimento presente neste processo de "colheita de crentes", aspirantes à celebrização, é o caminho seguido por muitos "descartados" da peopolização, que reenvia a mais uma via para a mitomania, o suposto poder de "saber" interpretar o horóscopo e de perceber bem os signos, que não pode ser desligado do tema que neste texto se aborda.

o jogo perigoso das interações entre forças racionais e forças irracionais, nos fenómenos de massa contemporâneos, parece ser proveniente de condições sociais e culturais bem mais universais, e vem demonstrar que a pseudociência dos astros é uma chave que permite compreender as inclinações sociais e psicológicas, hoje largamente difundidas. 0 jogo jornalístico, ao qual se entrega o íntimo dos astros, evacua de facto, em permanência, como demonstra Adorno (Adorno, 2000), a conjetura, a alimentação e a exploração das necessidades de um público dependente, projetando esta dependência sobre fenómenos exteriores, seja uma intriga de manipuladores da Bolsa ou uma constelação celeste.

O que lança as gentes para os braços dos diferentes tipos de "profetas da impostura", escreve Adorno, não é apenas o seu sentimento de dependência e o seu desejo de colocar esta dependência na conta de forças "superiores" e, em definitivo, mais aceitáveis, é também o seu desejo de reforçar esta dependência, e não tomar nas suas 
próprias mãos a resolução dos seus problemas. Em resumo, a astrologia não exprime somente a dependência, é uma ideologia da dependência, uma tentativa de reforçar e de qualquer maneira justificar as peníveis condições da existência.

10 Mas existem coisas mais graves. Reflexo da opacidade da realidade empírica, a astrologia é, por si própria, tão opaca que pode ser facilmente aceite por pessoas céticas e desencantadas. 0 culto de Deus foi substituído pelo culto dos factos. O que caminha a par com a crescente fé nos acontecimentos é o facto de a informação ter tendência a substituir cada vez mais a investigação e a reflexão intelectuais, o elemento de síntese, no sentido filosófico clássico, está cada vez menos presente, de maneira que legitimamente podemos afirmar, com Adorno, que a astrologia é a moeda a pagar por se ter negligenciado o pensamento interpretativo a favor do lucro da coleta dos fins.

11 Esta predisposição do público para dar crédito a semelhantes convicções patenteia-se em diferentes formas de expressão, entre os vários fenómenos periféricos à peopolização. $\mathrm{Na}$ ocorrência, o objeto principal deste texto, acima referido: a mitologia da telenovela e do telemóvel, um portento de sublimação, e substituição menor, de quem não pode aceder ao mundo people, pressuposto que, em circunstância alguma, não coloca em questão a importância do fenómeno da evasão lúdica, e do lazer, e da necessidade de comunicação "ubiquista" entre seres humanos.

12 "Sê tu próprio, sendo igual ao padrão" parece ser o apelo vindo de origens várias, concedendo aos "crentes" a possibilidade ilusória de ser people. Telenovelas e telemóveis são, a meu ver, a outra face da cultura das aparências, independentemente do interesse e da centralidade sociocomunicacional, que estas duas expressões mitómanas adquirem na quotidianeidade, mundanidade e globalização.

13 A variante das telenovelas e das séries televisivas, tal como do telemóvel, deve ser olhada, entre outras óticas, como a expressão travesti da impossibilidade absoluta de os aspirantes à peopolização poderem aceder ao elenco dos atores da telenovela ou da série, daí o recurso a outras vias que proporcionem semelhante "grandeza", sem esquecer, aqui, as redes sociais, outro "parente pobre" da peopolização, ou seja, como alternativa à frustração provocada pela impossibilidade de serem olhados como figuras people. Figurar aí permite a ilusão de viver outra vida, uma fantasia criada pelo fenómeno da peopolização.

14 Qualquer das vertentes aqui explanadas, como alternativas e complementos, devem ser vistas não como um absoluto, que absolutamente envolve todos os incondicionais da peoplefilia, ao mesmo tempo da telenovela, do telemóvel e das redes sociais, mas com algum relativismo, sem generalizações abusivas, em função da sua utilização instrumental, vista como ligada ao trabalho.

15 Seja como for, esta variável apresenta recortes com enorme contributo para a compreensão dos efeitos psicossociais da peopolização, um processo no qual os obstáculos, que vão surgindo, obrigam à procura de outras vias de transferência, criando as sucessivas, e também concorrenciais, mitologias da telenovela, do telemóvel e redes sociais, como formas de exibição, face às frustradas tentativas de hipervisibilidade. Ou seja, na impossibilidade de aceder ao quadro da peopolização, na necessidade e urgência de evidência, recorre-se à ostentação, que tem várias formas de expressão, segundo as posses materiais.

16 Julgo ter razão quando abordo a situação paradigmática dos dependentes das telenovelas ou séries televisivas. 
17 Senão, vejamos. Quando regressam ao domicílio, começam por desligar o telefone, dispõem travessas com pratos de refeição sobre os joelhos, e refugiam-se no fundo do sofá, frente ao televisor. "Ensurdecem" se alguém bate à porta. Em caso de "urgência", utilizam eventualmente os intervalos publicitários para telefonar. Estes "subjugados" amam este ritual de preparação, como se este fosse, identicamente, ligado a um grande momento de igualitarismo com os atores, de cumplicidade e intimidade com os companheiros no visionamento da telenovela ou da série. O seu maior prazer é combinar a vida na telenovela, ou na série, e a vida real. Os pontos comuns são numerosos e a conduta das personagens serve facilmente de modelo ou de contramodelo. Estes comportamentos imaginários são para os dependentes das telenovelas, ou séries, incarnações das suas próprias tentativas de solução de vida face às dificuldades da existência. As séries, as telenovelas, para divertir os verdadeiros adeptos, parecem ter necessidade do apoio de pequenas comunidades de espectadores, onde se relata, rememora e comenta. Como escreve o sociólogo inglês Fiske, o sucesso da televisão, em particular das séries e telenovelas, é devido em parte à facilidade com a qual os seus programas podem ser inseridos nas formas de cultura oral (Fiske e Hartley, 1989).

Dito de outro modo, o primeiro grande sucesso do género serial é ter começado a propor mundos ficcionais que vêm partilhar a nossa intimidade. $O$ fenómeno não é novo.

Depois de meados do século XIX, a industrialização massiva do mundo e a alfabetização das classes médias e populares, a necessidade de ficção e o desejo de percorrer mundos ficcionais, também ricos, desenvolvidos e diferentes quanto possível, são patentes (Thiesse, 2000).

20 Após o desenvolvimento da imprensa, sobretudo a partir da segunda década do século XIX, os actores em confronto procuram recrutar público em todos os meios sociais. Um processo que inicia o seu aprofundamento no século XIX e tem o seu auge no século XXI, na cultura da celebridade, pivô da segunda modernidade. Na essência, o mito é uma palavra, como afirma Barthes, que conduz à escuta e à interpretação. Escutar o espírito do tempo para descriptar os objetos e os signos nos quais ele incarna (Barthes, 2001: 215).

21 Em Portugal, a leitura de periódicos do século XIX dá-nos conta de como o "círculo de leitura" (leitor, auditor e espectador) dos jornais, com maior tiragem, em que o romance-folhetim, publicado assiduamente, sobretudo a partir de meados do século XIX, é de leitura obrigatória e, ao mesmo tempo, agregador de leitores. Com efeito, associado à ilustração do periódico, surge mais uma inovação, como instrumento de captação de leitores: o romance-folhetim, que garante um novo público, indiferente às variações da política, mas apaixonado pela prosa de aventuras e as histórias de amor. É uma modalidade que rapidamente se difunde para o exterior, cujo objetivo, para além do comercial, é alcançar como que uma densidade próxima do real vivido através da exploração da ficção, do mistério, do romance negro, do suspense, desempenhando ao mesmo tempo funções de escape de tensões sociais (o mesmo irá depois acontecer com o foto-romance e a fotonovela). Deste modo, foi revelado aos futuros criadores da grande imprensa popular um dos meios mais seguros de cimentar um público cada vez mais alargado e, conjuntamente, estimular a sua atenção, até aí indiferente, para assuntos de interesse geral que envolviam a Sociedade Civil e o Estado. A empatia entre público e periódico, com epicentro no folhetim, encaminha a outro tipo de leituras, no 
qual se inscreve o uso público da razão e a polarização de uma parte dos novos leitores/ auditores/espectadores em torno da res publica (Alves, 2005: 132).

Os folhetins filmados, e. g., Fantômas ou Les Vampires, de Louis Feuillade (1873-1925), encheram também as salas de cinema dos anos dez do século XX. As coleções de livros melodramáticos, a preço reduzido, entusiasmaram inumeráveis leitores de toda a espécie.

Hoje, a televisão e, particularmente, as séries e as telenovelas ganharam irreversível dianteira. É provável que as dificuldades da vida contemporânea amplifiquem a necessidade de mundos imaginários no interior dos quais é bom viver. 0 género da série televisiva, por muito pouco que se tome a sério, está perfeitamente desenvolvido para responder a este desejo. Os admiradores de séries parecem, desde a adolescência, muito pouco dependentes dos discursos públicos críticos ou outros a propósito dos seus heróis. Com toda a frontalidade, são indiferentes às opiniões dos seus pais ou dos seus professores sobre a inanidade suposta de tudo o que se passa sobre o pequeno, cada vez maior, ecrã. Os amantes de séries parecem contentar-se em amar e saborear com os seus amigos os seus objetos preferidos. Este facto não impede os "seriófilos" ou "telelenovelófilos" de serem verdadeiros conhecedores. Eles são observadores precisos das formas narrativas das séries televisionadas (Esquenazi, 2009: 11).

Contudo, é preciso fazer notar que este interesse apaixonado pelas séries ou telenovelas diz respeito a todos os escalões etários e a todas as categorias sociais, pois, caso contrário, na ausência de público crente na salvação pela peopolização, as figuras people arriscavam a saída do proscénio, o afastamento irrecusável e a busca de outra corporização da hipervisibilidade, que outros, a quase totalidade, desejosos de figuração, tiveram de agenciar na telenovela e no recurso ao telemóvel, aos vários telemóveis, em resposta às solicitações do mercado. Não surpreendem por isso alguns números astronómicos, referidos a seguir, que nos deixam ver esta outra mitologia.

Se no mundo, em finais de 2009, havia mais de 4,6 mil milhões de assinantes de telemóvel, a geopolítica dos usos e dos mercados, do que é também chamado cellphone, handphone (USA), telefonino (Itália), handy (Alemanha), não deve permanecer inédita na história das inovações tecnológicas.

26 Trago aqui à colação, entre outros, alguns exemplos, para apontar a extraordinária dimensão deste prodígio de crescimento.

27 Assim, em África, por mil milhões de habitantes, 300 milhões de africanos têm acesso (muitas vezes por partilha de um mesmo telemóvel) a um telemóvel, com uma taxa de penetração de $30 \%$ a $90 \%$, segundo os países [http://bit.ly/6fULV9]. Por exemplo, na África do Sul, para 47 milhões de habitantes, registam-se 42 milhões de telemóveis, enquanto há 3 milhões de internautas e 13 milhões de indivíduos têm uma conta no banco [http://bit.ly/zjqnw].

28 Na Índia, contam-se 400 milhões de assinantes de telemóvel, duas vezes mais nas zonas urbanas que nas regiões rurais, o que representa um terço da população, mas constitui o recorde mundial da conectividade à rede de telefónica com 15 milhões de conexões por mês.

29 Assim, na hora de interrogar esta nova mitologia, $64 \%$ de todos os telemóveis encontram-se nos países emergentes [http://bit.ly/7Vln61], onde apenas se contabilizam 305 milhões de computadores e onze milhões de camas de hospital (Allard, 2010: 6-8). 
30 Portugal e o Brasil não fogem a esta tendência que parece desenvolver-se em progressão geométrica. Os dados estatísticos são elucidativos sobre o enorme crescimento do número de telemóveis e utilizadores.

31 Em 2010, de acordo com a Agência Nacional de Telecomunicações (Anatel), o número de telemóveis no Brasil supera os 197 milhões, um dado que indica, em média, mais de um telemóvel por habitante. O número de utilizadores nas comunicações móveis aumentou, em Novembro de 2010, para 3,09 milhões, o que representa um aumento de 1,59\% face ao mês anterior e um acréscimo de 17,55\%, quando comparado com o mesmo período do ano de 2009, revela o mesmo organismo brasileiro.

32 Em comparação, os números têm outra dimensão, bem menor, no que respeita ao acesso à internet de banda larga móvel. A Anatel revela que "o Brasil registou 19,45 milhões", no mês em análise, com a operadora Claro a liderar com uma quota de mercado de $39,83 \%$, seguida pela Vivo, que tem $32,10 \%$ do mercado. A Oi surge em quarto lugar neste segmento, com uma quota de mercado de 5,47\% (Jornal de Negócios Online, 2010).

33 No que diz respeito a Portugal, as operadoras móveis continuam a conquistar clientes. Em 2009, segundo a Autoridade Nacional de Comunicações (Anacom), existiam em Portugal 15,929 milhões de assinantes do Serviço Telefónico Móvel (STM), o que representa um aumento de 2,4\% face ao trimestre anterior e de 6,5\% em termos homólogos. De acordo com a mesma fonte, o peso dos cartões pós-pagos, 4,341 milhões, atingiu cerca de $27,2 \%$ do total de assinantes, tendo registado um crescimento de mais de 4 pontos percentuais nos últimos 2 anos. Segundo as projeções da Research and Markets, uma empresa que produz e comercializa estudos de mercado, o número de subscritores de números de telemóvel em Portugal passará dos 15,929 milhões, em 2009, para um total de 17,2 milhões em 2014.

34 Mais elementos, sobre a utilização de telemóveis, poderiam ser trazidos à colação, mas, por economia do presente texto, limito-me a este conjunto de indicadores, que, a meu ver, parece suficiente para se ter uma ideia sobre a dimensão desta nova mitologia da segunda modernidade.

\section{Conclusão}

35 No seio desta móvelevasão, que há de comum entre o vulgar cidadão, que trabalha nas linhas de montagem de telemóveis, de telenovelas e de computadores, e o comunicador do capitão Kirk, de Star Trek, que inspirou o protótipo do telemóvel em 1973, por Martin Cooper? Uma mitologia que se construiu a partir do velho sonho da comunicação ubiquista, sem fios, aos usos expressivos de uma tecnologia polifuncional e personalizada, que dá poder aos pobres, às mulheres, aos homens, sem resolver, contudo, os seus problemas. Nunca uma inovação tecnológica se difundiu tão rápida e globalmente.

o continente africano adotou massivamente o telemóvel - enquanto a internet está ainda mal desenvolvida -, com taxas de penetração próximas dos países do Norte, em certos países do Sudeste Africano (Allard, 2010: 9). A Índia não foge à regra. Brasil e Portugal estão no mesmo caminho.

37 Assim, face à origem e expansão desta nova mitologia, são inegáveis, também, as experiências pessoais e sociais em curso pelo mundo e as promessas democráticas que 
abre este objeto já mitificado em que parece o telemóvel ter-se tornado, sem esquecer outras instrumentalizações, como as abordadas neste texto.

Na verdade, na ausência de outra possibilidade de ostentação e evidência, o telemóvel é também, para além da extrema funcionalidade e utilidade, uma forma menor de peopolização, um simulacro, se pode dizer-se, que a substitui, um desejo de peopolização do seu possuidor, impedido do acesso a outras corporizações, em função dos seus proibitivos custos materiais.

Finalmente, pode dizer-se que, no impedimento de ingresso no quadro da celebrização e de "tornar-se" people, os "crentes" na salvação pela peopolização encontram nas telenovelas uma forma de viver uma ilusão e, no telemóvel, a necessidade e urgência de visibilidade, recorrendo à exibição, que tem várias formas de representação.

Na impossibilidade de chegar aos desfiles de moda, ser interveniente em telenovelas, descartada qualquer possibilidade de peopolização, o refúgio e a fantasia são a telenovela, com o seu aparente poder do "saber" telenovelesco, e o telemóvel, vários modelos, muitas vezes, em resposta às pretensões do mercado. Em derradeira instância, são formas de mitigar as frustrações dos objetivos malsucedidos, dos delírios desfeitos, a expressão catártica da sua finitude, uma perspetiva que não pode ser vista de modo absoluto, sem, contudo, lhe retirar o caráter universal da sua proficuidade.

\section{BIBLIOGRAFIA}

ADORNO, T. W. (2000), Des étoiles à la terre: la rubrique du Los Angeles Times. Étude sur une superstition secondaire, Traduction française, Paris, Exils Editeur, in http://www.chapitre.com/CHAPITRE/fr/ BOOK/adorno-theodor-wiesengrund/des-etoiles-terre-a-terre-etude-sur-l-astrologie-et-lasuperstion,1610545.aspx

Agência Financeira, 2010-08-20, in http://www.agenciafinanceira.iol.pt/media-e-tecnologia/ telemoveis-brasil-utilizadores-agencia-financeira/1185939-2974.html

ALLARD, L. (2010), Mythologie du portable, S. l., Le Cavalier Bleu éditions, coll. Myth'O.

ALVES, J. A. S. (2005), o Poder da Comunicação. A história do poder dos media: dos primórdios da imprensa aos dias da Internet, Lisboa, Casa das Letras.

BARTHES, R. (2001), Mythologies, Paris, Seuil.

DAKHLIA, J. (2010), Mythologie de la peopolisation, S. 1., Le Cavalier Bleu éditions, coll. Myth'O.

ESQUENAZI, J.-P. (2009), Mythologie des séries télé, S. 1., Le Cavalier Bleu éditions, coll. Myth'O.

FISKE, J. (1987), Television Culture (Studies in Communication Series), Londres, Methuen \& Co. Ltd.

FISKE, J. (1989), Understanding Popular Culture, Londres: Routledge.

FISKE, J. e J. Hartley (1989), Reading television, Londres e Nova Iorque, Routledge.

Jornal de Negócios Online, 21 Dezembro 2010, in http://www.jornaldenegocios.pt/home.php? template $=$ SHOWNEWS_V2\&id $=459771$ 
Jornal de Negócios Online, 09 Março 2011, in http://www.jornaldenegocios.pt/home.php?template $=$ SHOWNEWS_V2\&id=410805

THIESSE, A.-M. (2000), Le roman du quotidien: lecteurs et lectures populaires à la Belle-Époque, Paris, Éd. du Seuil.

WOLTON, D. (2006), É preciso salvar a comunicação, São Paulo, Paulus.

WOLTON, D. (2007), Sauver la communication, Paris, Flammarion.

\section{NOTAS}

1. O "buzz" é a experiência de jogo social que já vendeu milhões e ganhou prémios da British Academy of Film and Television Arts (BAFTA) e que traz diretamente, para a sala de estar, a emoção dos programas de quiz, em exclusivo nos formatos Playstation. Quiz é uma forma de avaliar uma grande quantidade de pessoas com um questionário com respostas do tipo "certo ou errado" e chegar a um consenso geral. Existem vários tipos de quiz: o que funciona como inquérito pessoal sobre uma pessoa, ou o que tem perguntas que levam a um resultado em comum.

\section{RESUMOS}

Como definir peopolização? Peopolização é o nome dado por Dominique Wolton às práticas dos meios de comunicação que fortalecem a chamada sociedade do espetáculo, como o reality show, com o culto das celebridades, mesmo que sejam celebridades produzidas, instantâneas e efémeras. Numa primeira abordagem, sobre a base de um sobreinvestimento coletivo da celebridade, a peopolização surge como um mito naïf, segundo o qual a celebridade representa o summum da realização pessoal e do sucesso social. A eficácia deste mito está próxima de um certo número de candidatos da tele-"realidade" ou de "microcelebridades" da tela, cuja principal aspiração "na vida" é "tornar-se" people, como se tratasse de uma profissão ou de uma vocação. Neste contexto, é necessário constatar que a maioria do público se entrega com bem-aventurança a esta crença na salvação pela peopolização. Este tipo de "fé" manifesta-se em outras exteriorizações, e. g., os signos e o horóscopo, que é o caminho seguido por muitos "descartados" da peopolização. A predisposição do público para dar crédito a semelhantes convicções patenteiase, ainda, em diferentes formas de expressão, entre os vários fenómenos periféricos à

peopolização. Estão neste o caso a mitologia da telenovela e do telemóvel.

How to define peopolization? Is the name given by Dominique Wolton to the media practices that strengthen the society of the spectacle, as the realty show, with the cult of celebrity, even if they are instant celebrities produced, and ephemeral. A first approach on the basis of a collective of overinvestment celebrity peopolization, emerges as a naif myth, according to which the celebrity summum represents the personal achievement and the social success. The effectiveness of this myth is near of a certain number of candidates of tele-"reality" or "screen" microcelebrities, whose main goal "in life" will be to become "people", as if it were a profession or a vocation. In this context, it is necessary to note that the majority of the audience delivery himself to this belief in salvation, by peopolization. This sort of "faith" has others exteriorisations such as signs 
and horoscopes, which are the path followed by many "dropped peopolization". The public's willingness to give credit to similar convictions has other forms of expression in peripheral phenomena to peopolization. In this case, they are the mythology of the soap opera and the mobile phone.

ÍNDICE

Keywords: peopolization, show business, soap opera, cell-phone

Palavras-chave: peopolização, show business, telenovela, telemóvel

\section{AUTOR}

\section{JOSÉ AUGUSTO DOS SANTOS ALVES}

Centro de História da Cultura, Faculdade de Ciências Sociais e Humanas, Universidade Nova de Lisboa (jsalves@fcsh.unl.pt) 